\title{
Results from Two Years of Ka-band Propagation Characterization at Svalbard, Norway
}

\author{
James Nessel, Jacquelynne Morse, Michael Zemba \\ NASA Glenn Research Center, Cleveland, $\mathrm{OH}$, USA
}

\begin{abstract}
Over the next several years, NASA plans to launch several earth science missions which are expected to achieve data throughputs of 5-40 terabits per day transmitted from low earth orbiting spacecraft to ground stations. The current S-band and $\mathrm{X}$-band frequency allocations in use by NASA, however, are incapable of supporting the data rates required to meet this demand. As such, NASA is in the planning stages to upgrade its existing Near Earth Network (NEN) polar ground stations to support Ka-band (25.5-27 GHz) operations. Consequently, it becomes imperative that characterization of propagation effects at these NEN sites is conducted to determine expected system performance, particularly at low elevation angles ( $<10 \mathrm{deg}$ ) where spacecraft signal acquisition typically occurs. Since May 2011, NASA Glenn Research Center has installed and operated a Ka-band radiometer at the NEN site located in Svalbard, Norway. The Ka-band radiometer monitors the water vapor line, as well as 6 frequencies around $26.5 \mathrm{GHz}$ at multiple elevation angles: 45deg, 20deg, and 10deg. Two-year data collection results indicate comparable performance to previously characterized northern latitude sites in the United States, i.e., Fairbanks, Alaska. It is observed that cloud cover at the Svalbard site remains the dominant loss mechanism for Ka-band links, resulting in a margin requirement of $4.1 \mathrm{~dB}$ to maintain link availability of $99 \%$ at $10 \mathrm{deg}$ elevation.
\end{abstract}

Index Terms-radiometer, RF propagation measurements, Ka-band, polar climate.

\section{INTRODUCTION}

NASA's architecture for the Near Earth Network (NEN) calls for upgrades to operational Ka-band in the 2018 timeframe to support throughputs of $1.2 \mathrm{Gbps}$ at Low Earth Orbit (LEO)/Middle Earth Orbit (MEO), $150 \mathrm{Mbps}$ at L2, and 25-70 Mbps at distances ranging from LEO to the Moon [1]. These mission requirements are driven by the manifest of upcoming earth science, lunar robotic, and human exploration missions expected to be launched in the near future [2]. Since 2010, the implementation of these new Ka-band services via the NEN network has been investigated, which includes the characterization of Ka-band propagation effects at the northern polar network located in Svalbard. Ka-band data at these northern latitudes and low elevation angles is limited, and a concerted effort was undertaken by NASA to characterize the Svalbard site to determine the expected link margins and system availability for the imminent Ka-band communications system upgrades. Since May 2011, NASA Glenn Research Center (GRC), in collaboration with Goddard Space Flight Center (GSFC) and Kongsberg Satellite Services (KSAT), has installed and operated a Ka-band radiometer at the Svalbard site. Svalbard was chosen as the appropriate site for two primary reasons: (1) Svalbard will be the first site to be upgraded to Ka-band operations within the NEN Polar Network enhancement plan, and (2) there exists a complete lack of Ka-band propagation data at this site (as opposed to the Fairbanks, AK NEN site, which has 5 years of characterization collected during the Advanced Communications Technology Satellite (ACTS) campaign). Herein, we discuss the two-year measurement results from the ongoing Ka-band propagation characterization campaign at Svalbard and compare these results with existing data from a comparable northern latitude site (Fairbanks, AK), as well as with current ITU-R models. Comparison of results indicates good agreement with low elevation angle data collected during the ACTS campaign in Alaska, but significant deviation from predictions performed by the NASA NEN Ka-band planning team. Issues for these deviations from model predictions are discussed.

\section{SVALBARD EXPERIMENT DESCRIPTION}

The NASA Ka-band propagation terminal, designated SG61, is located at the east end of the Svalbard NEN complex as shown in the aerial photograph in Figure 1. The operational equipment at SG61 consists of a Radiometrics PR2330 Polarimetric Radiometer and a weather station, which are shown in Figure 2 (a) and (b), respectively.

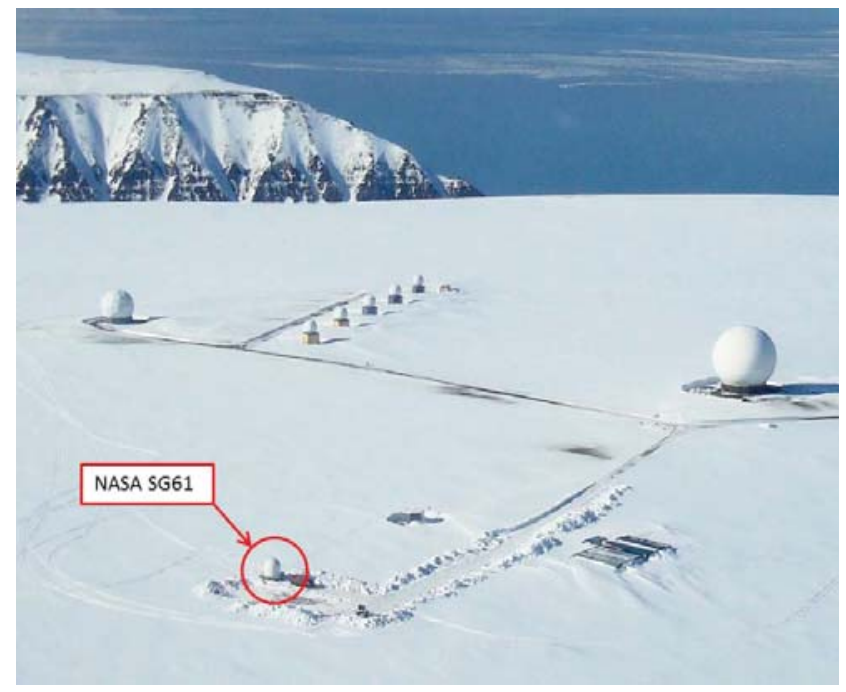

Figure 1. Aerial photograph of the Svalbard NEN site showing the location of SG61. 


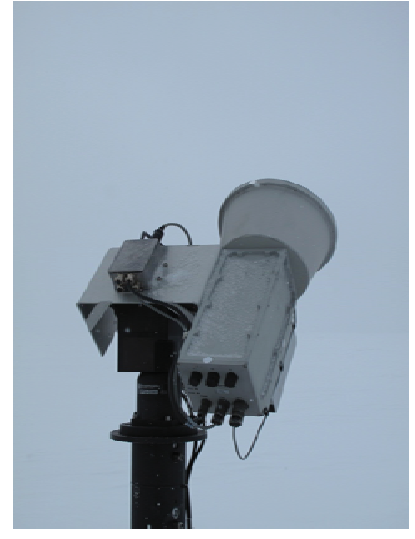

(a)

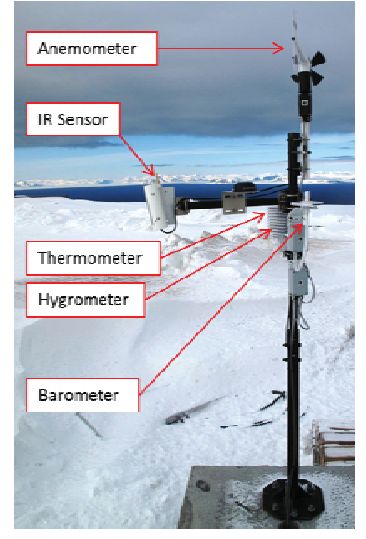

(b)
Figure 2. (a) Photograph of Radiometrics PR-2330 Polarimetric Radiometer, and (b) photograph of weather station at SG61.

\section{A. SG61 Hardware Description}

The Radiometrics PR-2230 is a high-resolution, single polarization, 22 to $30 \mathrm{GHz}$ radiometer with a 3-degree halfpower beamwidth (HPBW) antenna, optimized for high performance in harsh, extreme environments. An internal Baseband Processor controls the radiometer state sequence and timing, maintains thermal stability, collects and processes all data, and communicates with the user via two serial ports. An internal accelerometer, in tandem with the pan and tilt positioner, provides pointing accuracy to 0.1 -degrees. System gain and receiver temperature are measured continuously and applied to the transfer function in real time to generate accurate calibrated brightness temperatures with no lengthy calibration interruptions. A 4 point calibration and non-linear transfer function are used to compensate for small, finite system linearity errors [3]. A block diagram of the PR-2230 radiometer is shown in Figure 3 and a summary of the operational specification of the unit is provided in Table 1 [3].

The PR-2230 can be programmed to observe multiple channels (up to 21 unique frequencies) over the $22-30 \mathrm{GHz}$ band, and records the measured power at each frequency sequentially through the Digital Intermediate Frequency (IF) Module swept controller (see Figure 3). A pre-detection channel bandwidth of $300 \mathrm{MHz}$ and a $1 \mathrm{sec}$. integration time provide a brightness temperature resolution of $<0.5 \mathrm{~K}$. An infrared (IR) sensor is also affixed to the radiometer for cloud detection along the direction of observation.

The local weather station consists of a suite of Young sensors measuring local temperature, pressure, humidity, and wind velocity, as well as a secondary, zenith-pointing ClarityII IR sensor which measures cloud base temperature to identify the presence of clouds. The consistent subzero temperatures at the site makes rain rate measurements very unreliable, therefore, a tipping bucket was not included as part of the weather measuring instruments.

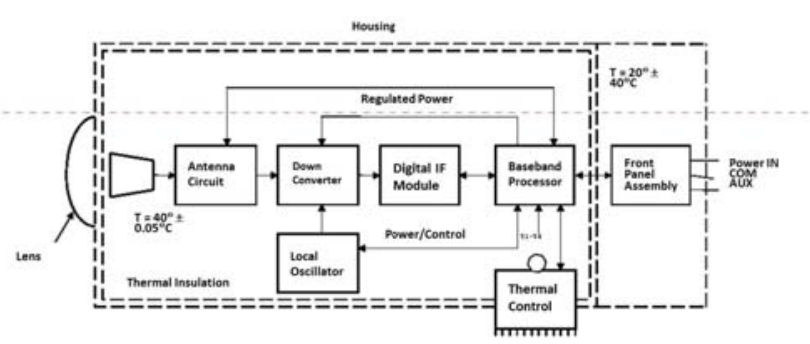

Figure 3. Block diagram of the Radiometrics PR-2230 Polarimetric Radiometer.

Table I. Performance Specifications of Radiometrics PR-2230 Polarimetric Radiometer [3].

\begin{tabular}{|l|c|}
\hline \multicolumn{1}{|c|}{ Parameter } & Specification \\
\hline $\begin{array}{l}\text { Calibrated Brightness Temperature } \\
\text { Accuracy }\end{array}$ & $0.2+0.002^{*} \mid$ Tref - Tsky $\mid \mathrm{K}$ \\
\hline Long Term Stability & $<1.0 \mathrm{~K} / 0.5 \mathrm{yr}$ (typ.) \\
\hline $\begin{array}{l}\text { Resolution (dependent on integration } \\
\text { time) }\end{array}$ & 0.1 to $1 \mathrm{~K}$ \\
\hline $\begin{array}{l}\text { Integration Time } \\
\text { (user selectable in } 10 \text { msec increments) }\end{array}$ & 0.01 to $2.5 \mathrm{sec}$ \\
\hline Brightness Temperature Range & $0-400 \mathrm{~K}$ \\
\hline $\begin{array}{l}\text { Antenna System Optical Resolution and } \\
\text { Side Lobes }\end{array}$ & $3^{\circ} /-24 \mathrm{~dB}$ \\
\hline Frequency Agile Tuning Range & $22.0-30.0 \mathrm{GHz}$ \\
\hline Standard Calibrated Channels & 21 \\
\hline Pre-detection Channel Bandwidth & $300 \mathrm{MHz}$ \\
\hline $\begin{array}{l}\text { Surface Sensor Accuracy } \\
\left.\text { Temperature (-50 to 50 }{ }^{\circ} \mathrm{C}\right)\end{array}$ & $0.5^{\circ} \mathrm{C} @ 25^{\circ} \mathrm{C}$ \\
Relative Humidity $\left(0-100^{\circ}\right)$ & $2 \%$ \\
Barometric Pressure $(800$ to $1060 \mathrm{mb})$ & $0.3 \mathrm{mb}$ \\
Infrared Thermometer (IRT) & $\left(0.5+0.007^{*} \Delta \mathrm{T}\right){ }^{\circ} \mathrm{C}$ \\
\hline $\begin{array}{l}\text { Calibration Systems } \\
\text { Primary Standards } \\
\text { Operational Standards }\end{array}$ & $\begin{array}{c}\text { TIP method } \\
\text { Noise Diode }+ \text { ambient Black } \\
\text { Body Target }\end{array}$ \\
\hline
\end{tabular}

\section{B. Radiometer Operations}

As part of normal operations, the PR-2230 Polarimetric Radiometer monitors 4 channels across the operational Kaband bandwidth at 25.5, 26, 26.234, and $26.5 \mathrm{GHz}$, as well as two channels to measure the water vapor line at 22.234 and 30 $\mathrm{GHz}$, with a 1 second integration time at each frequency. This results in an absolute radiometer resolution of $<0.5 \mathrm{~K}$. Sky tip calibrations are performed daily at 0:03 GMT, wherein 4 elevation angles are measured at each of two opposing azimuth directions (to smooth out atmospheric inhomogeneities). An internal processor determines whether the tip calibration is successful, where success is defined as having an R2 value greater than 0.99 for a linear fit of the sky tip data. A representative tip calibration curve based on data taken on August 30, 2013, is plotted in Figure 4 below. The linear fit resulted in $\mathrm{R}^{2}=0.99$, indicating a successful tip calibration. 


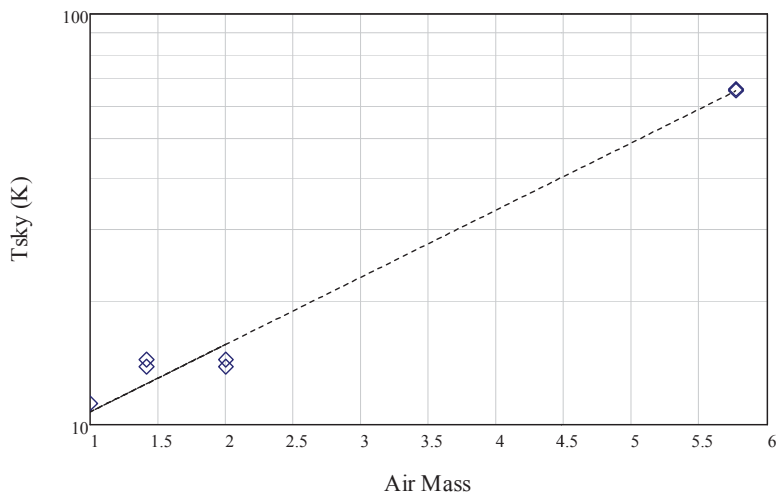

Figure 4. Successful tip calibration curve for Aug. 30, 2013 showing data and linear fit. $\mathrm{R}^{2}=0.99$.

In accordance with the NEN Ka-band planning team's requirement of low elevation angle observations, the radiometer first monitored brightness temperatures at a fixed elevation angle of $45^{\circ}$ from May 2011 to October 2011. For the following 2 months, the elevation was set to $20^{\circ}$, after which, from December 2011 to present, an angle of $10^{\circ}$ was monitored. Results reported herein discuss the entirety of data collection, with an emphasis on the validation and results at the $10^{\circ}$ elevation angle.

Attenuation, in $\mathrm{dB}$, is derived from the calibrated radiometer brightness temperature using the simplified radiative transfer relation,

$$
A=10 \log \left(\frac{T_{M}-T_{C}}{T_{M}-T_{B}}\right)
$$

where $\mathrm{T}_{\mathrm{C}}$ is the cosmic background temperature, taken to be $2.75 \mathrm{~K}, \mathrm{~T}_{\mathrm{B}}$ is the measured brightness temperature, and $\mathrm{T}_{\mathrm{M}}$ is the atmospheric mean radiating temperature, which, based on historical data at Svalbard, is taken to be a constant $275 \mathrm{~K}$. A representative plot for a week of attenuation and relevant weather data in July 2013 is provided in Figure 5. From the plot, we observe a week of mostly cloudy days, with the exception of approximately 12 hours on July $30^{\text {th }}$, when the IR sensor dropped below $200 \mathrm{~K}$. The effect of the presence of clouds on the attenuation measurement is also evident in the time series.

\section{MeAsurement Results}

\section{A. Svalbard Site Attenuation Statistics}

For the purposes of NASA's Near Earth Network Ka-band planning team, we are interested in the expected performance of ground systems operating at Ka-band at low elevation angles $\left(<10^{\circ}\right)$ where initial link acquisition occurs with polar orbiting LEO satellites. The Cumulative Distribution Function (CDF) of the radiometer-derived attenuation at Svalbard at $10^{\circ}$ elevation angle is shown in Figure 6 for all monitored frequencies. From the plot, we observe little difference in attenuation across the $1 \mathrm{GHz}$ band from 25.5 to
26.5 GHz, and higher attenuation at $22.234 \mathrm{GHz}$. This is expected, due to the shape of the water vapor absorption line. At the higher percent availabilities, we further observe that the attenuation curves for the 25.5-30 GHz frequencies approach, but not surpass, the water vapor absorption attenuation values, indicating that, for most of the time, the cloud contribution to attenuation are due to thinner, low liquid water content clouds. This is also expected based on the dry northern climate.
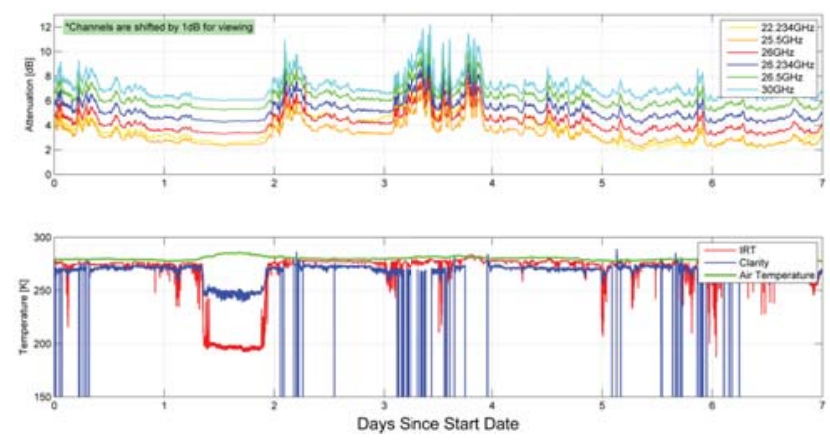

Figure 5. Plot of 1 week of attenuation data (top) and cloud sensor data (bottom) from 7/29/13 to 8/4/13 at SG61. Note: attenuation plots are shifted by $1 \mathrm{~dB}$ for viewing purposes.

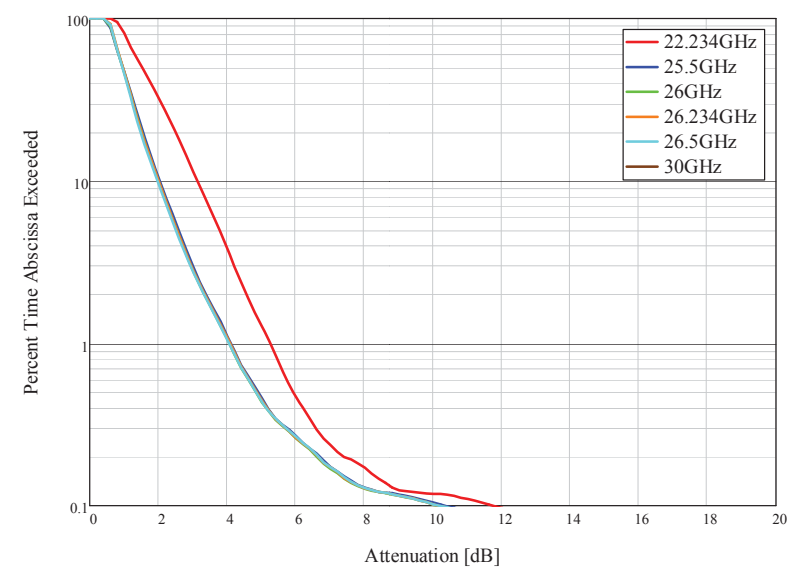

Figure 6. CDF of radiometer-derived attenuation at Svalbard at $10^{\circ}$ elevation angle for 2011-2013.

An assessment of the cloud cover contribution to attenuation at Svalbard can be performed via the IR sensors at SG61. A CDF of a Cloud Index parameter is generated, which is simply the differential temperature between the surface temperature and the IR sensor temperature. Based on radiometric observations at Svalbard, a Cloud Index of approximately $50 \mathrm{~K}$ represents a good indicator to delineate between cloudy and clear sky conditions. From the plot in Figure 7 , it is observed that, on average, $70 \%$ of the time, there exists significant cloud cover at the Svalbard site, with slightly better conditions in the Spring and Winter (December-May) vs. the Fall and Summer (June-November) months. 


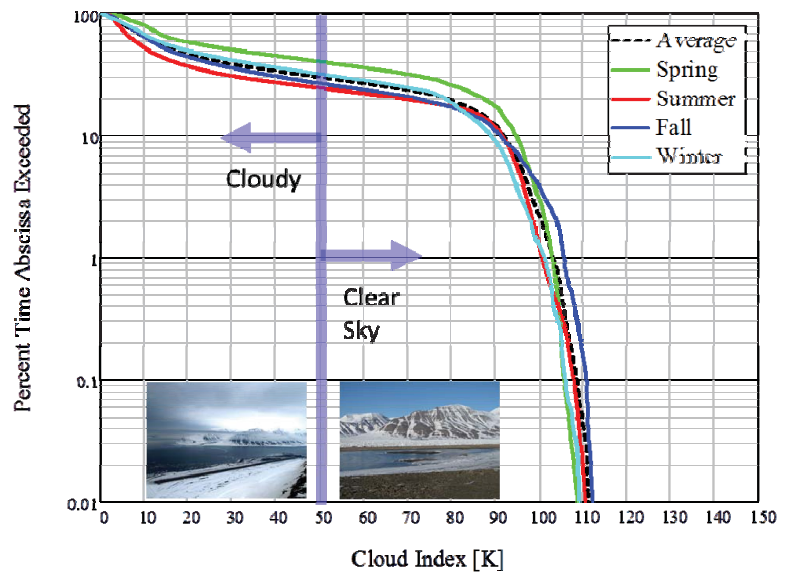

Figure 7. Average and seasonal CDF of Cloud Index Parameter used to define clear vs. cloudy sky conditions.

\section{B. Validation of Results}

Since a radiometer passively measures the black-body emissions of all components integrated over the antenna field of view, low elevation angle observations can potentially be corrupted by ground emissions within the sidelobes of the antenna pattern (also referred to as antenna spillover). Unfortunately, multiple elevation angle measurements were not taken sequentially for a given data set to allow for a direct detection of this effect, but we can still observe whether or not the effect is dominant by analysing the longer term statistics of the different elevation angle measurements for clear sky days. By comparing the measured and scaled data at a common $10^{\circ}$ elevation angle, the presence of significant ground emission corruption in the measurement would manifest itself in an inflated average attenuation in the measured data over the scaled data. In Figure 8, the measured attenuation $\mathrm{CDF}$ at $10^{\circ}$ is compared with the scaled attenuation CDFs at $20^{\circ}$ and $45^{\circ}$. From these results, we confirm that the close agreement between measured and scaled data for clear sky days, as well as the lower overall average attenuation at the measured $10^{\circ}$ elevation angle, indicates that antenna spillover is not a significant factor for the low elevation angle characterization.

We can also compare the results obtained from the radiometer-derived attenuation with beacon-based data taken at a similar climatological zone. During the Advanced Communications Technology Satellite (ACTS) program, Kaband propagation data were collected at Fairbanks, AK, at 27 $\mathrm{GHz}$ and an $8^{\circ}$ elevation angle. Figure 9 shows a comparison of the average attenuation CDFs for both Svalbard and Alaska, where the Alaska data have been scaled via the airmass relationship to $10^{\circ}$ for comparison purposes. From the plot, it is readily observed that the results of the two campaigns show good agreement, indicating that, as expected, the similar polar climates of the two sites result in comparable attenuation predictions. The increased attenuation in Alaska observed at the higher availabilities is due to the inherent inability of the radiometer to accurately characterize attenuation due to rain.

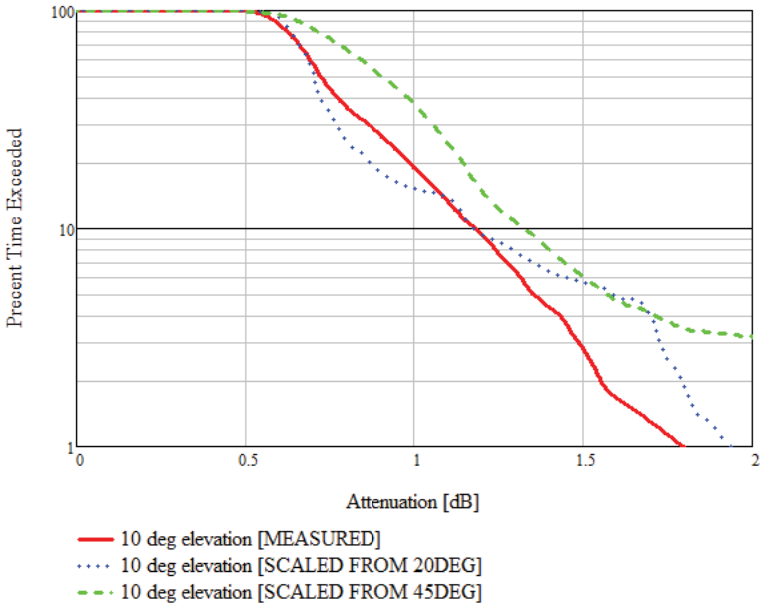

Figure 8. Comparison of attenuation CDFs for data collected at $10^{\circ}$, $20^{\circ}$, and $45^{\circ}$ scaled to a common $10^{\circ}$ elevation angle.

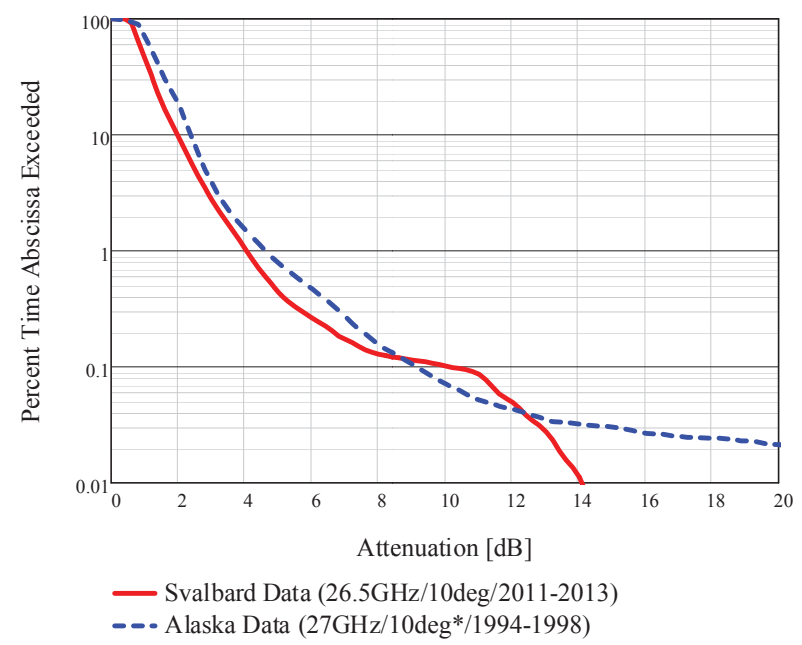

Figure 9. Comparison of measured average attenuation CDFs for Fairbanks, AK, and Svalbard at $10^{\circ}$ elevation angles. * Note the Alaska data is scaled to $10^{\circ}$ from the original observation angle of $8^{\circ}$ for comparison purposes.

However, rain statistics in Svalbard indicate that occurrences of rain are relatively rare and would therefore have a minimal effect on availability.

\section{Comparison of Results with ITU Models}

With good agreement observed between measurements taken at the Fairbanks site during the ACTS campaign, and the Svalbard site, today, it is worthwhile to compare the data to the attenuation predicted by the ITU models. Figure 10 shows a plot of the ITU derived attenuation at Svalbard based on 2010 rain rate maps and cloud statistics, taking into account the attenuation contributions from gaseous absorption, cloud attenuation, and rain attenuation [2]. Table 2 provides values for comparison between the ITU model and radiometric-based measurement at the $95 \%, 97 \%$, and $99 \%$ 
availability levels. The ITU model shows surprisingly accurate predictions of atmospheric attenuation when compared to measurements at Svalbard. Based on the planned $3 \mathrm{~dB}$ link margin being designed for Svalbard, therefore, we expect acquisition at 10 deg elevation angle to be successful, on average, $97 \%$ of the time.

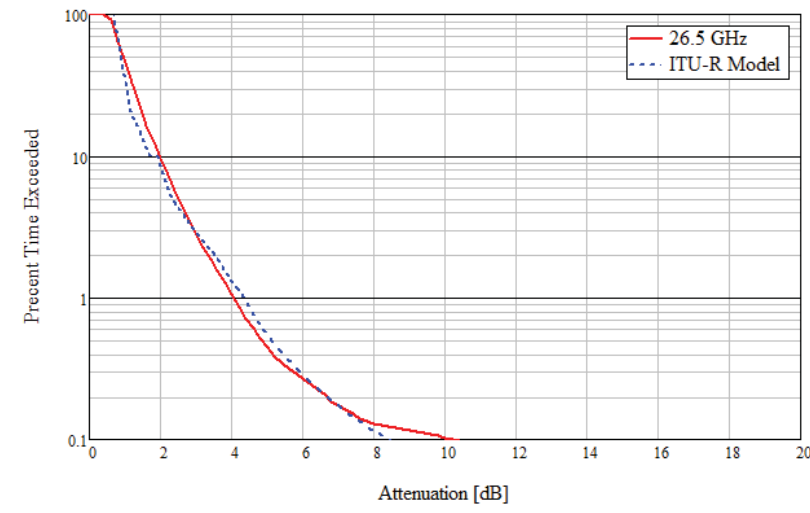

Figure 10. Comparison of ITU-predicted and radiometer-derived attenuation statistics at Svalbard at 10 deg elevation angle for December 2011-2013.

Table II. Comparison of ITU-R Model Predicted and Measured Attenuation at 95\%, 97\%, and 99\% Availability for Svalbard [2].

\begin{tabular}{|c|c|c|c|c|}
\hline \multicolumn{2}{|c|}{$\begin{array}{l}\text { Model vs. Measurement } \\
\text { @10 deg elevation }\end{array}$} & $\begin{array}{c}95 \% \\
\text { Availability } \\
\text { Attenuation }\end{array}$ & $\begin{array}{c}97 \% \\
\text { Availability } \\
\text { Attenuation }\end{array}$ & $\begin{array}{c}99 \% \\
\text { Availability } \\
\text { Attenuation }\end{array}$ \\
\hline \multirow[t]{2}{*}{$\begin{array}{l}\text { Svalbard, } \\
\text { Norway }\end{array}$} & $\begin{array}{l}\text { Model } \\
\text { (Expected) }\end{array}$ & $2.3 \mathrm{~dB}$ & $2.9 \mathrm{~dB}$ & $4.3 \mathrm{~dB}$ \\
\hline & $\begin{array}{l}\text { Measured } \\
\text { (Actual) }\end{array}$ & $2.5 \mathrm{~dB}$ & $2.9 \mathrm{~dB}$ & $4.1 \mathrm{~dB}$ \\
\hline
\end{tabular}

\section{CONCLUSIONS}

Earth- and space-science missions in the foreseeable future will require Ka-band communications to support their extremely high data rate requirements, and NASA is already planning ahead to upgrade the existing infrastructure to support Near Earth operations, particularly for low earth orbiting polar satellites. Part of this initiative involves determining the system specifications necessary to maintain a given level of availability, which is highly dependent on the propagation characteristics of the atmosphere. For the past 2 years at the polar NEN site in Svalbard, NASA GRC has been measuring Ka-band propagation data at low elevation angles and has identified a link margin requirement of approximately $4.1 \mathrm{~dB}$ to accommodate a $99 \%$ availability level at this site for acquisition at $10 \mathrm{deg}$ elevation angles. This measured attenuation agrees extremely well with that predicted by the ITU models. Based on an expected $3 \mathrm{~dB}$ link margin for the Svalbard site, a link acquisition at the 10 deg elevation angle is expected to occur with $97 \%$ availability.

\section{REFERENCES}

[1] Space Communications and Navigation Network Architecture Definition Document: Volume 1, Rev. 2, Oct. 2011.

[2] Recommendation ITU-R P.618-10, "Propagation data and prediction methods required for the design of Earth-space telecommunication systems," Oct. 2009.

[3] Radiometrics Corporation PR Series Radiometer Handbook, Chapter 3, p.1-3, 2011 